\title{
Gas embolism during endoscopic retrograde cholangiopancreatography: diagnosis and management
}

\author{
Gandhi Lankea, Douglas G. Adler \\ Plains Regional Medical Center, Clovis, New Mexico; University of Utah School of Medicine, Salt Lake City, Utah, USA
}

\section{Abstract}

\section{Introduction}

Gas embolism is defined as the undesired entry of air into the vascular structures which can be venous or arterial. Gas embolism is usually air, but it can be carbon dioxide, nitrous oxide, nitrogen or other gases. Air embolism is often a catastrophic event which can lead to significant morbidity and mortality. It is usually iatrogenic and can occur during any endoscopic procedure including esophagogastroduodenoscopy, colonoscopy, enteroscopy, sigmoidoscopy, endoscopic ultrasound, surgical procedures, intravenous catheterization, radiologic procedures, positive pressure ventilation, trauma,

aPlains Regional Medical Center, Clovis, New Mexico (Gandhi Lanke); ${ }^{b}$ Department of Gastroenterology and Hepatology, University of Utah School of Medicine, Salt Lake City, Utah (Douglas G. Adler), USA

\section{Conflict of Interest: None}

Correspondence to: Douglas G. Adler MD, FACG, AGAF, FASGE, Professor of Medicine, Director of Therapeutic Endoscopy, Director, GI Fellowship Program, Gastroenterology and Hepatology, University of Utah School of Medicine, Huntsman Cancer Center, 30N 1900E 4R118, Salt Lake City, Utah 84132, USA, e-mail: Douglas.adler@hsc.utah.edu

Received 20 July 2018; accepted 12 October 2018; published online 20 December 2018

DOI: https://doi.org/10.20524/aog.2018.0339 and decompression sickness [1-10]. Endoscopic retrograde cholangiopancreatography (ERCP) is a complex gastrointestinal procedure wherein a side-viewing upper endoscope is used to pass into the duodenum to facilitate instruments to access biliary and pancreatic duct. Various indications of ERCP include the treatment of biliary obstruction, acute biliary pancreatitis with cholangitis, stent placement for benign and malignant strictures, pancreatic pseudocyst drainage, and tissue sampling from pancreatic or bile ducts [11]. Complications of ERCP include pancreatitis, cholangitis, hemorrhage, and duodenal perforation [12]. Air embolism should be considered in the differential diagnosis of a patient with abrupt change in vitals or neurological status during or after ERCP. In this article, we review the etiology, pathophysiology, diagnosis, and management of air embolism in ERCP.

\section{Pathophysiology}

Gas embolism can be venous, paradoxical or arterial and the pathophysiology is described in Fig. 1 [12-16]. Physiological intrapulmonary right to left shunts, retrograde flow via superior vena cava into the cerebral veins, and passage of air via pulmonary veins into the left atrium can lead to paradoxical air embolism [17-20]. Large venous gas embolism can cause fatal cerebral artery gas embolism even in the absence of 
intracardiac defects [21]. Spencer et al demonstrated that the size of the bubble, surface tension, and vascular pressure influence the passage of emboli across the lungs [22]. Also, the partial pressure of gas inside the bubble determines the rate of dissolution in the blood. They also showed that equivalent doses of oxygen or carbon dioxide did not cross the lungs compared with nitrogen because of differences in partial pressure and surface tension.

In endoscopy, air insufflation under pressure into an exposed vessel (gastric ulcer) can lead to air embolism [23]. Maximum flow rates during endoscopy without resistance for purified water is $100 \mathrm{~mL} / \mathrm{min}$ and for air it is $2000 \mathrm{~mL} / \mathrm{min} \mathrm{[23].}$ Lowdon et al described a case report of air embolism in a patient who had previously undergone Kasai procedure (hepatoportoenterostomy) for biliary atresia. The authors concluded that air embolism developed by the entry of air into the hepatic veins below the enterostomy site [17].

The various proposed mechanisms for air embolism from ERCP include endoscope-induced mechanical irritation of the bile duct wall, air entry into the bilio-venous shunts, transgression of air into adjacent veins from inflammation of the mucosa, and muscular wall, leakage of air into the portal or hepatic venous system from the bile duct secondary to pressure in the biliary system via contrast injection, removal of bile duct stents, mechanical irritation of the bile duct from bile duct stones, preexistent bilio-venous fistula, and communication via sphincterotomy to the portal vein [24,25] (Fig. 1). Portal vein cannulation can also occur from laceration of small portal vein or trauma to papilla and is more common in pancreatic adenocarcinoma patients, likely from neo-angiogenesis or aberrant vessels [26-28].

\section{Clinical presentation}

Clinical suspicion is key in the diagnosis of air embolism as most of the patients are sedated during the procedure and hence diagnosis is based on objective signs, although most cases of air embolism go undiagnosed acutely given the severity and rapidity of clinical deterioration patients often experience. Many cases are only diagnosed post-mortem. Minor cases of venous air embolism can be asymptomatic but most severe cases can be lethal. Air can be detected in retinal vessels and areas of sharply defined pallor can be noticed on the tongue [29]. Cardiovascular signs and symptoms include chest pain, dizziness, crackles, elevated jugular venous pressure, acute onset right side heart failure, tachycardia or bradycardia, hypotension, mill wheel murmur (loud churning sound likely from mixing of air and blood in the right ventricle heard throughout the cardiac cycle), cardiac arrest, arrhythmias like supraventricular tachycardia, ventricular tachycardia, ventricular fibrillation, asystole, and pulseless electrical activity [30-34]. Neurological signs and symptoms include headache, seizures, focal neurological deficits, acute change in mental status or failure to regain consciousness after the procedure, hemiparesis, conjugate eye deviation, pupillary dilation, paraplegia, quadriparesis, skin mottling, bilateral extensor plantar reflex, and coma [35-38] (Fig. 2). Pulmonary symptoms and signs include respiratory failure, tachypnea, cyanosis, rales, and wheezing [39].

\section{Diagnosis}

Diagnosis should be based on clinical suspicion as no imaging is sufficiently accurate [16] sometimes the first clue to the diagnosis of air embolism during ERCP in intubated patients is drop in end-tidal carbon dioxide $\left(\mathrm{etCO}_{2}\right)$ [40]. The fall in etCO level (normal range $35-45 \mathrm{mmHg}$ ) can be detected by capnography. Air embolism leads to ventilation perfusion mismatch which further leads to increased physiological dead space and eventually to fall in et $\mathrm{CO}_{2}$. Hypoxia is a universal finding in air embolism and any sudden drop in oxygen saturation should be evaluated immediately. Hypotension occurs due to decreased venous return. Elevated central venous pressure (CVP) is a result of air embolism causing right ventricular strain leading to right heart failure [41]. Routine complete blood count with differential, comprehensive metabolic panel, creatine kinase, brain natriuretic peptide and troponin should be ordered. Although elevated hematocrit (Hct) can be nonspecific, it can be seen in arterial gas embolism likely secondary to endothelial injury leading to leakage of intravascular fluid and elevated Hct [42]. Low platelet count with elevated creatine kinase (CK) can be seen in air embolism $[43,44]$. Thrombocytopenia is explained by direct air bubble and platelet binding [45]. Also, pulmonary air embolism leads to platelet aggregation because of complement activation from the release of endothelin, serotonin, and thromboxane [43]. Elevated CK-MB is commonly seen in diving-associated gas embolism likely from skeletal air embolization [44]. CK occurs in 3 different isoenzymes: $\mathrm{MM}, \mathrm{MB}$, and BB. CK-MM is more common in skeletal muscle, $\mathrm{CK}-\mathrm{MB}$ in cardiac muscle, and $\mathrm{CK}-\mathrm{BB}$ in brain tissue. Electrocardiogram (ECG) shows non-specific ST and T wave changes. ST-segment depression or elevation can occur which suggests myocardial ischemia [46]. Arterial blood gas shows hypoxemia and hypercarbia.

Chest $\mathrm{x}$-ray findings include air in pulmonary artery, characteristic of pulmonary venous air embolism, pulmonary edema, adult respiratory distress syndrome, diminished vascularity in the upper lobes (air emboli common in upper lobes), intracardiac air, and atelectasis [47,48]. Computed tomography (CT) of the chest shows air in the pulmonary artery, heart and right ventricle $[31,49,50]$. CT of the abdomen can show air in the portal vein if the portal vein is cannulated (Fig. 3) [51]. CT of the brain shows intraparenchymal gas, midline shift, cerebral edema, and uncal herniation (Fig. 4) [52]. Magnetic resonance imaging (MRI) of the brain shows acute infarcts in the areas affected by air embolism [37]. Echocardiogram can identify air in cardiac chambers, patent foramen ovale (PFO), atrial septal defect, right ventricular dilation, decreased systolic function and pulmonary artery hypertension [53]. Transesophageal echocardiography (TEE) is more sensitive than transthoracic echocardiography in 


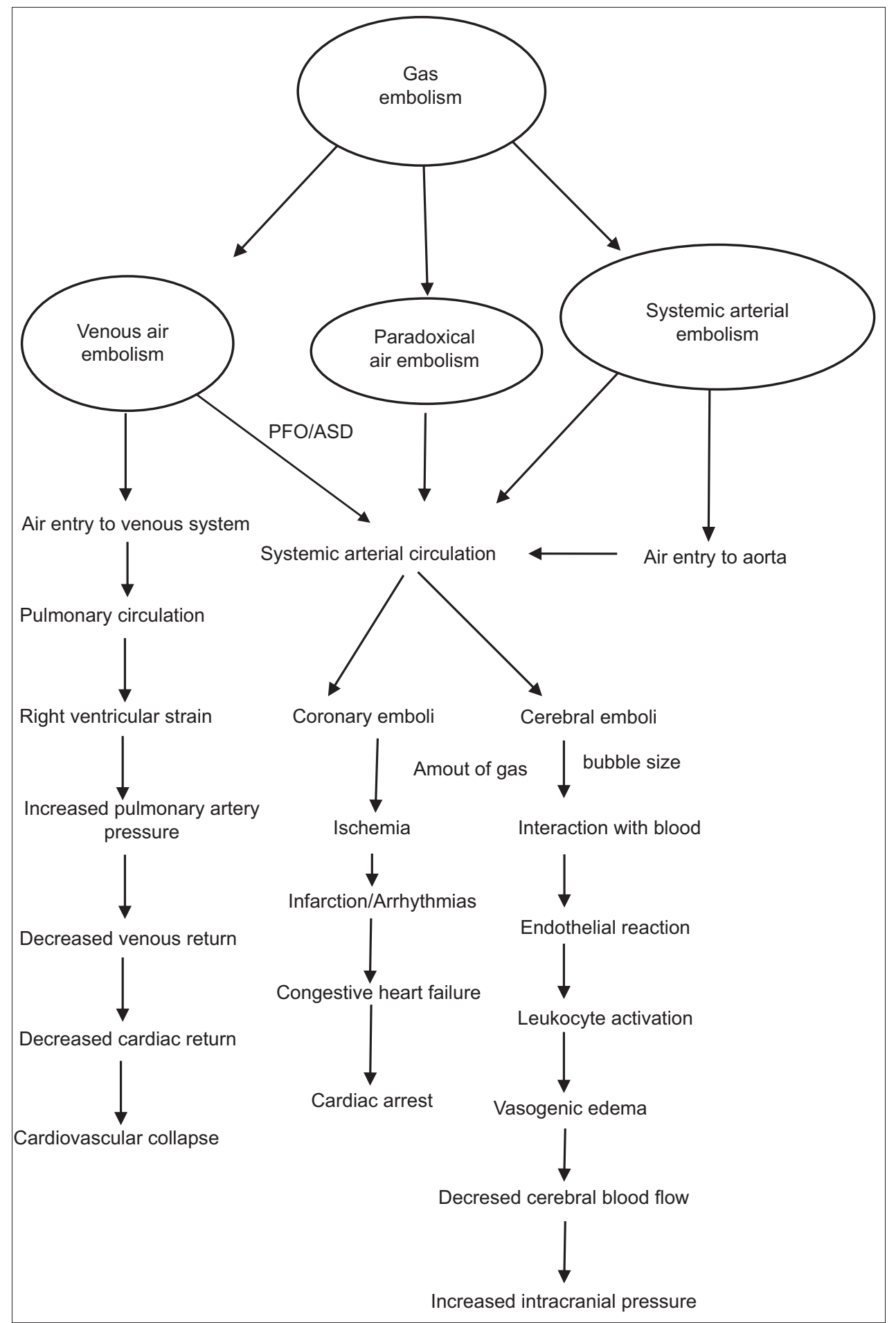

Figure 1 Pathophysiology of air embolism

PFO, patent foramen ovale; ASD, atrial septal defect

identifying PFO [54]. TEE is invasive, expensive and needs experienced personnel to do immediately [55]. Pulmonary embolism (PE) on TEE can be identified as global hypokinesis with mobile echogenic densities in the right atrium and right ventricle [40]. Precordial Doppler ultrasonography is sensitive in diagnosing air embolism and is noninvasive [56,57]. It is based on the principle that the Doppler ultrasonic signal from the transducer is reflected by moving red blood cells and cardiac structures, further electronically converted to an audible sound. The transducer is placed with a small amount of acoustic gel 
4 G. Lanke et al

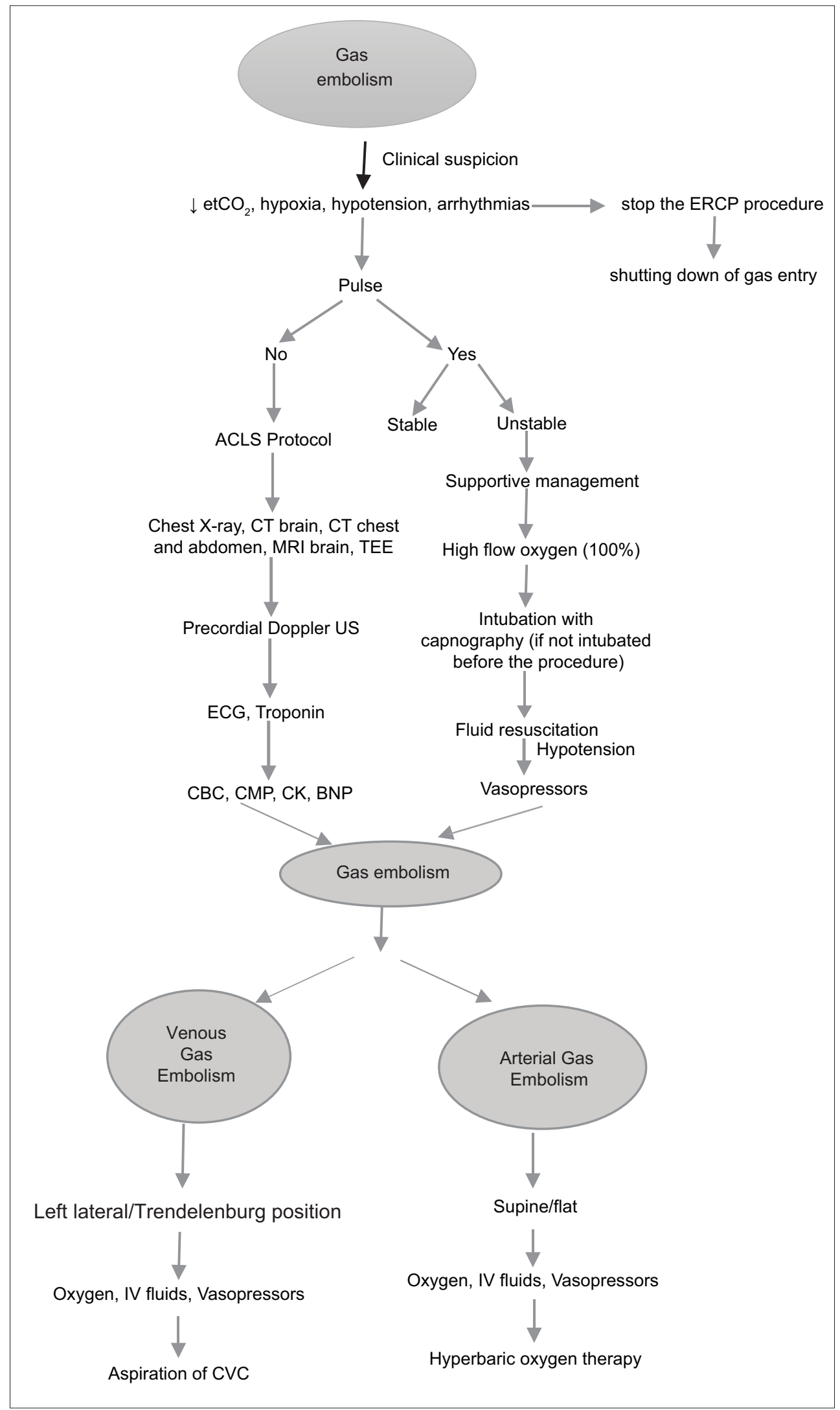

Figure 2 Proposed algorithm for diagnosis and management of gas embolism

MRI, magnetic resonance imaging; ACLS, advanced cardiac life support; ERCP, endoscopic retrograde cholangiopancreatography; TEE, transesophageal echo; $C B C$, complete blood count; CMP, complete metabolic panel; $C K$, creatine kinase; ECG, electrocardiogram; BNP, brain natriuretic peptide 


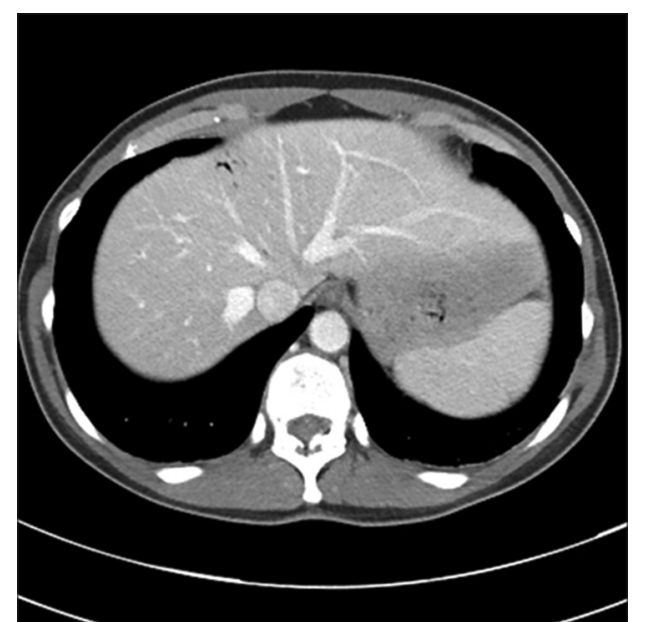

Figure 3 Computed tomography scan showing portal venous air embolism (Image courtesy Akram Shabaan, MD)

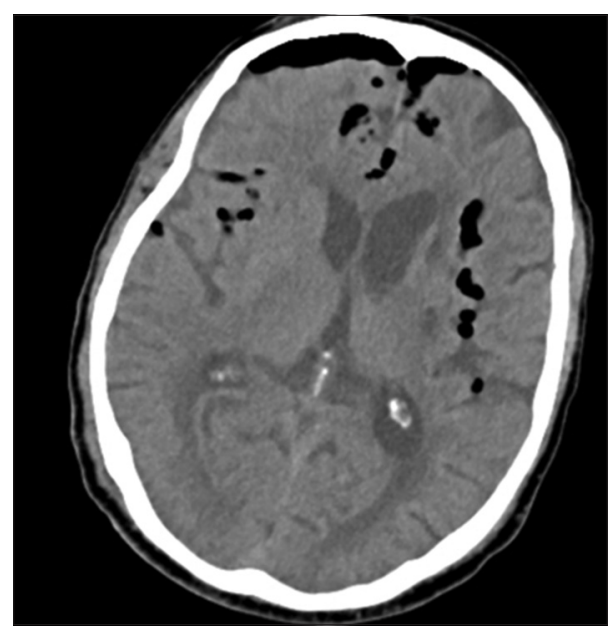

Figure 4 Computed tomography scan showing brain air embolism (Image courtesy Akram Shabaan, MD)

to the right side of the sternum between $3^{\text {rd }}$ and $4^{\text {th }}$ intercostal space, usually a few inches above the xiphoid process [58]. This position closely correlates with the placement of the transducer over the right atrium or right ventricle. Once the position of the transducer is confirmed it is secured with a circumferential rubber strap to avoid changes in Doppler signal with respiratory movements. A high pitched, "chirping", "scratchy", "roaring" sound is characteristic of air embolus [57]. A transient chirp is produced by small air embolus but raucous 'static' is usually produced by large air embolus. The disadvantage of precordial ultrasound Doppler is that it may be difficult to use in prone or lateral position [55]. Failure of Doppler signal can be due to slippage of the transducer especially in lengthy procedures or entrainment of air bubbles leading to decreased audible signal from the ultrasound [59]. Pulmonary artery catheter (PAC) can be used to detect air embolism. It is slightly more sensitive than etCO ${ }_{2}$, but it is invasive [59]. The increase in pulmonary artery pressure correlates with the amount and rate of air entrapment [55]. However, insertion of PAC is not practical in all cases as it needs more time and trained personnel and it is not well suited for aspiration of air from right atrium because of small atrial lumen $[60,61]$.

\section{Management}

We were able to identify 51 cases of air embolism during or after ERCP published in literature shown in Tables 1, 2, 3 and 4). A proposed algorithm for diagnosis and management of gas embolism is included in Fig. 2. The key in management is early recognition of signs and symptoms of air embolism, although in many cases the diagnosis is only made post-mortem [62]. Termination of the procedure should be the first step in the treatment to prevent further entry of gas. Decompression of the stomach and duodenum by withdrawal of the endoscope will reduce the pressure gradient and prevent further additional entrapment of air. Hemodynamic and respiratory stabilization should be the priority. Cardiopulmonary resuscitation should be initiated immediately when needed. Endotracheal intubation with capnography should be performed in somnolent, obtunded or comatose to protect airway and provide adequate ventilation and oxygenation.

High flow 100\% oxygen should be administered not only to treat hypoxia but also to help eliminate gas from bubbles by creating a diffusion gradient $[63,64]$. Placing the patient in left lateral (Durant) and Trendelenburg position will not only minimize the air embolism to brain but will also help force it out of the right ventricle $[13,35]$. As a result of these positions, the right ventricular outflow tract is placed inferior to the right ventricle cavity and air will migrate superiorly into the right ventricle making it less likely to embolize $[65,66]$. In arterial embolism, supine position is preferred as the buoyancy of air bubbles is not sufficient to overcome the blood flowing towards the head and head down position aggravates cerebral edema $[29,67]$. Evacuation of air from central venous catheter (CVC) is recommended if possible and occasionally up to $50 \%$ of entrained air can be removed with proper placement of CVC $[55,68]$. The optimal position of CVC for aspiration of air is at $2 \mathrm{~cm}$ below the junction of right atrium and superior vena cava $[55,69]$. Fluid resuscitation will increase CVP thereby preventing further entry of gas into the venous circulation [70]. Gas embolism can lead to hemoconcentration because of endothelial injury and leakage of intravascular fluid [42]. Animal studies in rabbits showed that minimal hemodilution (Hct approx. 30\%, target hemoglobin concentration $11 \mathrm{~g} / 100 \mathrm{~mL}$ ) reduces neurologic injury after cerebral ischemia compared with marked hemodilution (Hct $<30 \%$, target hemoglobin concentration $6 \mathrm{~g} / 100 \mathrm{~mL}$ ) [71]. The authors chose rabbits for their study as they closely resemble with the physiological characteristics of humans like arterial blood pressure, cerebrovascular response to change in $\mathrm{PaCO}_{2}$, arterial blood pressure and resting cerebral blood flow. This study is based on the hypothesis that cerebral blood flow and oxygen delivery is increased to ischemic tissues with minimal hemodilution but with marked hemodilution this protective effect is lost and further leads to greater cerebral infarct [72]. 
Table 1 Venous air embolism cases of ERCP published in literature

\begin{tabular}{|c|c|c|c|c|c|c|}
\hline Age $(\mathrm{M} / \mathrm{F})$ & Indication & Risk factor & Diagnosis & Treatment & Outcome & Shunt \\
\hline $79 \mathrm{~F}[30]$ & Ascending cholangitis & Previous biliary stent & Venous air embolism & Supportive & Dead & None \\
\hline $24 \mathrm{~F}[103]$ & Replace previous stent & Previous biliary stent & Venous air embolism & НВОТ & Alive & None \\
\hline $75 \mathrm{M}[104]$ & Obstructive jaundice & Previous biliary stent & Venous air embolism & НВOT & Alive & None \\
\hline $69 \mathrm{M}[105]$ & Common bile duct stone & $\begin{array}{l}\text { Endoscopic papillary balloon } \\
\text { dilation }\end{array}$ & Venous air embolism & НВОТ & Alive & None \\
\hline $51 \mathrm{~F}[31]$ & Common bile duct stone & Biliary sphincterotomy & Venous air embolism & Supportive & Dead & $\mathrm{PFO}$ \\
\hline $56 \mathrm{~F}[32]$ & Common bile duct stone & Biliary sphincterotomy & Venous air embolism & Supportive & Dead & None \\
\hline $55 \mathrm{~F}[49]$ & Common bile duct stone & Previous biliary stent & Venous air embolism & Supportive & Alive & None \\
\hline $87 \mathrm{M}[106]$ & Common bile duct stone & Biliary sphincterotomy & Venous air embolism & HBOT & Alive & None \\
\hline $8 \mathrm{M}[41]$ & $\begin{array}{l}\text { Removal of previous } \\
\text { biliary stent }\end{array}$ & $\begin{array}{l}\text { Portal cavernoma/ } \\
\text { Splenomes-enteric portal shunt }\end{array}$ & Venous air embolism & Supportive & Alive & None \\
\hline Not mentioned [107] & Common bile duct stone & Biliary sphincterotomy & Hepatic portal vein gas & Supportive & Alive & $\begin{array}{l}\text { Not } \\
\text { mentioned }\end{array}$ \\
\hline $31 \mathrm{M}[108]$ & Pancreatic duct stricture & Biliary sphincterotomy & Hepatic portal venous gas & Supportive & Alive & None \\
\hline $39 \mathrm{~F}$ [109] & Biliary pancreatitis & $\begin{array}{l}\text { Duodenal perforation/biliary } \\
\text { sphincterotomy }\end{array}$ & Portal venous gas & Supportive & Alive & None \\
\hline $68 \mathrm{M}[51]$ & Ascending cholangitis & Edematous papillae & Portal air & Supportive & Alive & None \\
\hline $74 \mathrm{~F}[110]$ & Ascending cholangitis & Gall bladder carcinoma & Portal air & Supportive & Alive & None \\
\hline $72 \mathrm{~F}[111]$ & Obstructive jaundice & pre-cut papillotomy & Portal air & Supportive & Alive & None \\
\hline $55 \mathrm{M}[62]$ & Common bile duct stone & Biliary sphincterotomy & Pulmonary-air embolism & Supportive & Dead & None \\
\hline $76 \mathrm{~F}[40]$ & Common bile duct stone & Previous biliary stent & $\begin{array}{l}\text { Pulmonary thrombo } \\
\text { embolism }\end{array}$ & Thrombolytic & Alive & None \\
\hline $43 \mathrm{~F}[112]$ & Obstructive jaundice & Biliary sphincterotomy & Pulmonary embolism & Supportive & Dead & None \\
\hline
\end{tabular}

ERCP, endoscopic retrograde cholangiopancreatography; $P F O$, patent foramen ovale; HBOT, hyperbaric oxygen therapy; $M$, male; $F$, female

Table 2 Systemic air embolism cases of ERCP published in literature

\begin{tabular}{|c|c|c|c|c|c|c|}
\hline Age $(\mathrm{M} / \mathrm{F})$ & Indication & Risk factor & Diagnosis & Treatment & Outcome & Shunt \\
\hline $66 \mathrm{M}[36]$ & CBD stone & Previous biliary stent & Systemic air embolism & Supportive & Dead & PFO \\
\hline $51 \mathrm{~F}$ [113] & Recurrent pancreatitis & Recurrent pancreatitis & Spinal air & Supportive & Alive & $\begin{array}{l}\text { Intra } \\
\text { atrial }\end{array}$ \\
\hline $65 \mathrm{M}[5]$ & Pancreatic duct stricture & Chronic pancreatitis & Cardiac air embolism & Supportive & Alive & None \\
\hline $82 \mathrm{M}[46]$ & Removal of CBD stent & Prior biliary stent & Systemic air embolism & Supportive & Alive & None \\
\hline $50 \mathrm{~F}[94]$ & CBD stone & Bilio-venous fistula/choledochoduodenostomy & Systemic air embolism & Supportive & Dead & None \\
\hline $72 \mathrm{~F}[114]$ & Diagnostic & Cholangiocarcinoma & Systemic air embolism & Supportive & Alive & None \\
\hline $53 \mathrm{M}[24]$ & CBD stone & Bilio-venous fistula & Systemic air embolism & Supportive & Alive & None \\
\hline $78 \mathrm{M}[115]$ & CBD stone & Bilio-duodenal fistula & Systemic air embolism & Supportive & Dead & None \\
\hline $82 \mathrm{~F}[116]$ & Bile duct stricture & Previous biliary stent & Systemic air embolism & НВОТ & Dead & None \\
\hline $27 \mathrm{M}[34]$ & Bile leak & Hepatic trauma & Systemic air embolism & НВОТ & Alive & None \\
\hline $63 \mathrm{~F}$ [117] & CBD stone & Biliary sphincterotomy & Systemic air embolism & Supportive & Dead & None \\
\hline $54 \mathrm{M}[118]$ & Biliary obstruction & Billroth II, previous biliary stent, chronic pancreatitis & Systemic air embolism & Supportive & Dead & None \\
\hline
\end{tabular}

ERCP, endoscopic retrograde cholangiopancreatography; PFO, patent foramen ovale; CBD, common bile duct; HBOT, hyperbaric oxygen therapy

There is no clear consensus on whether colloids are better than crystalloids in acute cerebral ischemia [73]. However, if there are signs of raised intracranial pressure or diffuse cerebral edema, hyperosmolar therapy with hypertonic saline $(3 \%$,
$7.5 \%$ or $23 \%$ ) is recommended [74]. Vasopressors should be initiated if blood pressure continues to be low even after fluid resuscitation. CVC placement is strongly recommended as it has an advantage of not only monitoring CVP (goal $12 \mathrm{mmHg}$ ) 
Table 3 Cerebral air embolism cases of ERCP published in literature

\begin{tabular}{|c|c|c|c|c|c|c|}
\hline Age $(\mathrm{M} / \mathrm{F})$ & Indication & Risk factor & Diagnosis & Treatment & Outcome & Shunt \\
\hline $85 \mathrm{M}$ [35] & Obstructed stent & Cholangiocarcinoma/Previous biliary stent & Cerebral air embolism & Supportive & Dead & None \\
\hline $37 \mathrm{M}[30]$ & CBD obstruction & Recurrent pancreatitis & Cerebral air embolism & Supportive & Dead & None \\
\hline 85 M [119] & Obstructed stent & Cholangiocarcinoma/Previous biliary stent & Cerebral air embolism & Supportive & Dead & None \\
\hline $45 \mathrm{M}[106]$ & Double duct stricture & Chronic pancreatitis & Cerebral air embolism & НВОТ & Alive & $\mathrm{PFO}$ \\
\hline $36 \mathrm{M}$ [37] & CBD stone & Previous biliary stent & Cerebral air embolism & Supportive & Alive & None \\
\hline $45 \mathrm{M}[38]$ & Ascending cholangitis & Alcoholic liver cirrhosis & Cerebral air embolism & Supportive & Dead & None \\
\hline $66 \mathrm{M}[113]$ & Bile duct stricture & Previous biliary stent & Cerebral air embolism & HBOT & Dead & PFO \\
\hline $58 \mathrm{~F}[52]$ & CBD dilatation & $\begin{array}{l}\text { Unsuccessful previous biliary stent/ } \\
\text { Cholangiocarcinoma }\end{array}$ & Cerebral air embolism & $\begin{array}{l}\text { Comfort } \\
\text { measures }\end{array}$ & Dead & None \\
\hline $45 \mathrm{M}[93]$ & Obstructive jaundice & Percutaneous transhepatic biliary drainage & Cerebral air embolism & Supportive & Alive & PFO \\
\hline $79 \mathrm{~F}[39]$ & CBD stone & Biliary sphincterotomy & Cerebral air embolism & Supportive & Alive & None \\
\hline $62 \mathrm{~F}[54]$ & CBD stone & Biliary sphincterotomy/Intraductal balloon dilation & Cerebral air embolism & Supportive & Alive & $\mathrm{PFO}$ \\
\hline $65 \mathrm{M}[33]$ & Bile duct stricture & Bilio-venous fistula & Cerebral air embolism & Supportive & Dead & None \\
\hline $60 \mathrm{~F}[120]$ & CBD stone & Biliary sphincterotomy/choledochal varices & Cerebral air embolism & Supportive & Alive & None \\
\hline $87 \mathrm{M}[118]$ & Bile duct stricture & Previous biliary stent & Cerebral air embolism & Supportive & Alive & PFO \\
\hline $56 \mathrm{M}[25]$ & Ascending cholangitis & Previous biliary stent/Biliary adenocarcinoma & Cerebral air embolism & $\begin{array}{l}\text { Comfort } \\
\text { measures }\end{array}$ & Dead & None \\
\hline $50 \mathrm{~F}[121]$ & CBD stone & Biliary sphincterotomy & Cerebral air embolism & HBOT & Dead & PFO \\
\hline $59 \mathrm{~F}[50]$ & Recurrent cholangitis & Choledochojejunostomy/Previous biliary stent & Cerebral air embolism & Supportive & Dead & $\mathrm{PFO}$ \\
\hline $82 \mathrm{M}[122]$ & CBD stone & Pancreatitis & Cerebral air embolism & Supportive & Dead & None \\
\hline
\end{tabular}

Table 4 Gas embolism from cholangioscopy published in literature

\begin{tabular}{lllllll}
\hline Age $(\mathrm{M} / \mathrm{F})$ & Indication & Risk factor & Diagnosis & \multirow{2}{*}{ Treatment } & Outcome & Shunt \\
\hline 68 F [97] & Hepatolith & Hepaticojejunostomy & Systemic air embolism & Supportive & Dead & None \\
Not mentioned [98] & Choledocholithiasis & Papillotomy/previous ERCP & Venous air embolism & Supportive & Dead & None \\
Not mentioned [98] & Cholangitis & papillotomy & Systemic air embolism & Supportive & Dead & None \\
\hline
\end{tabular}

ERCP, endoscopic retrograde cholangiopancreatography

but also to evacuate air. Seizures can occur with cerebral gas embolism and first line of treatment is benzodiazepines and phenytoin. However, if seizures are refractory, then barbiturates should be added. Barbiturates are shown to decrease oxygen consumption, intracranial pressure and the release of free radicals $[75,76]$.

Anticoagulation is not routinely recommended as there is risk of hemorrhagic transformation in the infarcted tissue. However, if PE is diagnosed, then anticoagulation is recommended. Risk factors for PE can be genetic or acquired. Genetic risk factors include factor $\mathrm{V}$ Leiden mutation and prothrombin gene mutation (G20210-A) [77]. Acquired risk factors can be provoked from recent surgery, trauma, immobilization, initiation of hormone therapy, and active cancer [78]. Unprovoked risk factors include obesity and heavy cigarette smoking [78]. Treatment choices for PE depends on whether the patient is hemodynamically stable or unstable. For stable PE, treatment choices include unfractionated heparin and low molecular weight heparin. Heparin can induce antibodies to platelets which can predispose to arterial and venous thrombosis [79]. When unfractionated heparin cannot be used, low molecular weight heparin is safe to use [80]. For unstable PE, treatment options include thrombolytic therapy, transvenous catheter embolectomy, inferior vena cava (IVC) filter and pulmonary embolectomy with or without cardiopulmonary bypass [81]. Thrombolytic therapy with tissue plasminogen activator (tPA), such as alteplase, streptokinase and urokinase, can be used in unstable PE when rate of clot resolution is critical. Absolute contraindications for tPA use include intracranial neoplasm, recent intracranial or spinal surgery or trauma (less than 2 months), history of a hemorrhagic stroke, active bleeding or bleeding diathesis, or nonhemorrhagic stroke within the previous 3 months. IVC filter placement is recommended when there is absolute contraindication to therapeutic anticoagulation or complication to anticoagulation. Surgical embolectomy is recommended in unstable PE when there is contraindication to tPA or failed thrombolysis. 
Corticosteroids are not recommended in cerebral gas embolism as they can potentiate ischemic injury to neurons [82]. In an effort to understand the cause of death in cerebral air embolism, studies on animals showed that autonomous nervous system could mediate cardiac arrhythmias. As a result, an animal study was done to evaluate the effect of lidocaine on cerebral air embolism. The role of lidocaine in humans is not clear, although prophylactic treatment with lidocaine in animal models showed benefit in cerebral air embolism by reduction in somatosensory evoked potential and intracranial pressure $[83,84]$. Hence, future studies on humans can potentially investigate the role of lidocaine in cerebral ischemia from air embolism. Therapeutic hypothermia in cerebral air embolism after cardiac arrest can be neuroprotective, more studies need to be done to make it standard of care in cerebral air embolism [85]. However, therapeutic hypothermia is not recommended in active infection or coagulation disorder $[38,86]$.

Hyperbaric oxygen therapy (HBOT) is recommended in severe cases of air embolism with hemodynamic compromise and neurologic deficits [70]. Hyperbaric oxygen is based on the principle of Boyle's law that surface area and volume of gas bubble is inversely proportional to pressure at constant temperature. HBOT provides $100 \%$ oxygen at a pressure above that of the atmosphere at sea level and the partial pressure of arterial oxygen is greater than $2000 \mathrm{mmHg}$ [70]. With increasing ambient pressure from HBOT, the gas bubble shrinks and leads to hyperoxia. Hyperoxia creates diffusion gradient which promotes oxygen into the bubble and nitrogen out of the bubble [67]. Hyperoxia also increases the extent of diffusion of oxygen into the tissues by dissolving large amounts of oxygen into the plasma [87]. HBOT has been shown to decrease cerebral edema by decreasing the adherence of leukocytes to damaged endothelium and by reducing the permeability of blood vessels $[88,89]$. The ideal time to initiation of HBOT is not clear, however patients who received HBOT within $5 \mathrm{~h}$ from the onset of symptoms are likely to have good recovery [90]. HBOT is generally safe when standard protocol of atmospheric pressure not more than 3 and maximum treatment exposure time of $120 \mathrm{~min}$ is used [91]. Most common side effect of HBOT is reversible myopia from direct toxic effect of oxygen on the lens [91].

\section{Risk factors}

Risk factors like previous biliary interventions, hepatobiliary surgery, portosystemic shunts, percutaneous transhepatic biliary drainage, liver abscess, blunt trauma to the liver, gastric ulcer, bilio-venous fistula, Billroth II or Roux-en-Y, should alert the endoscopist for possible air embolism during or after ERCP if they notice any signs or symptoms [34,49,92,93]. Sphincterotomy during ERCP can disrupt the gastrointestinal mucosal barrier and it can result in shunts between the veins in duodenal wall and intestinal cavity [94]. In patients with blunt hepatic trauma causing bile leak and lacerated hepatic veins, air/ $\mathrm{CO}_{2}$ insufflation during ERCP can potentially cause gas to enter into the IVC from the lacerated hepatic veins, although this is extremely rare in clinical practice [34]. Air embolism can travel into the right ventricle from the IVC and to the lungs leading to impaired gas exchange and cardiac failure. Budd-Chiari syndrome causes chronic inflammation from biliary strictures which potentially leads to bilio-venous fistula [49]. The risk of air embolism is increased during ERCP with preexisting bilio-venous fistula from air insufflation and sphincterotomy. Also, in patients with difficult cannulation during ERCP for obstructive jaundice who undergo percutaneous transhepatic cholangiography (PTC) are more prone to bilio-venous fistula which could be a risk factor for air embolism [93]. Cholangitis from biliary stones can lead to focal weakening of bile duct wall and adhesions with adjacent structures and are more prone to develop bilio-venous fistula, a high risk for air embolism [95]. According to Afreen et al, the incidence of air embolism is more in ERCP involving stent removal with replacement and cholangioscopy [96]. Cholangioscopy is sometimes used when there are equivocal ERCP findings to evaluate the extent of cholangiocarcinoma before surgery, biliary stones not identified by routine cholangiography, treatment of difficult bile duct stones and for evaluation of indeterminate biliary strictures $[97,98]$. Biliary stones and strictures cause inflammation which could lead to bilio-venous fistula and hence they are more prone to air embolism during cholangioscopy.

\section{Prophylactic measures}

Use of ERCP only when appropriately indicated can minimize the risk of air embolism. Air insufflation into the portal vein can occur during sphincterotomy and use of $\mathrm{CO}_{2}$ can minimize air embolism but more studies need to be done to standardize use of $\mathrm{CO}_{2}$ [99]. As ERCP is sometimes a lengthy procedure, the use of $\mathrm{CO}_{2}$ has an advantage of being rapidly absorbed into the intestinal mucosa with greater elimination through expiration, thereby helping deflate the bowel quickly $[100,101]$. Use of $\mathrm{CO}_{2}$ not only decreases bowel residual gas volume but also decreases abdominal discomfort and nausea after the procedure [100]. Endotracheal intubation with capnography during ERCP can play an important role in the early recognition of air embolism. When there is decrease in cardiac output from air embolism, capnography reveals a fall in etCO $\mathrm{CO}_{2}[30]$. Although it is not well studied if endotracheal intubation with capnography should be routinely offered to all patients who undergo ERCP but patients with risk factors can benefit from capnography for early recognition of air embolism. Use of precordial Doppler ultrasound can be beneficial in patients with risk factors to detect early air embolism during ERCP. The role of routine preprocedural evaluation for PFO in patients with risk factors who undergo ERCP is unclear and is not performed in routine practice. However, when ERCP is indicated in patients with $\mathrm{PFO}$ and risk factors, consideration of placement of CVC for evacuation of air from right atrium should be anticipated to prevent the complications from air 
embolism. Also, in patients who undergo repeat ERCP after PTC and if a fresh blood clot is noticed at the ampulla site which could be a sign of bilio-venous fistula, sphincterotomy should potentially be deferred to avoid air embolism and PTC drain should be left in place until the stent is placed [93]. Gastroscopes with distinct controls to infuse $\mathrm{CO}_{2}$ and saline with limits on rates of infusion can minimize the risk of air embolism.

The differential diagnosis of acute coronary syndrome (ACS), acute stroke, PE and cardiogenic shock should also be considered. ACS can be non-ST elevation myocardial infarction (NSTEMI) or ST elevation myocardial infarction (STEMI). ECG shows ST elevation in STEMI and emergency catheterization is warranted. However, in NSTEMI ECG shows non-specific ST and T wave changes or ST depression with elevated troponin. Treatment of NSTEMI includes antiplatelet agents like aspirin, clopidogrel, statin and anticoagulation with heparin or low molecular weight heparin if there are no contraindications. Cardiogenic shock can be from any acute cause of severe left ventricular or right ventricular dysfunction. Common causes include acute myocardial infarction like STEMI or NSTEMI or PE. Diagnosis is confirmed when there is hypotension (systolic blood pressure $<90 \mathrm{mmHg})$, cardiac index $(<1.8 \mathrm{~L} / \mathrm{min}$ per $\mathrm{m}^{2}$ ), hypoperfusion and elevated pulmonary capillary wedge pressure (>15 mmHg) [102]. Coronary angiography is recommended in patients with acute myocardial infarction for reperfusion. Echocardiogram shows severely depressed right ventricle or left ventricle or both. Acute stroke can present with signs and symptoms of acute change in mental status during or after the procedure, failure to regain consciousness after the procedure, focal neurological deficits like hemiparesis, paraplegia and quadriparesis. MRI is diagnostic, and it shows acute infarcts if there is stroke.

\section{Concluding remarks}

Although air embolism is rare, diagnosis is critical in the management to prevent severe morbidity and mortality. High risk factors should alert the endoscopist to anticipate air embolism so that it can be treated early. At the discretion of endoscopist and anesthesiologist, intubation with continuous end tidal capnography should be considered especially in patients with high risk factors undergoing ERCP, as fall in etCO $\mathrm{C}_{2}$ levels can often be the first clue in the diagnosis of air embolism. $\mathrm{CO}_{2}$ insufflation seems to be a better option than air to prevent air embolism, however more prospective studies are needed to show the benefit. Precordial Doppler ultrasound can often diagnose air embolism, although TEE is more sensitive. Supportive treatment and prompt use of HBOT in cerebral air embolism can improve the outcome. PE should always be considered in the differential diagnosis especially with hemodynamic instability. Multidisciplinary team involving endoscopist, anesthesiologist, radiologist, intensivist, surgeon, cardiologist and the ancillary staff is key in the management of air embolism.

\section{References}

1. McAree BJ, Gilliland R, Campbell DM, Lucas JW, Dickey W. Cerebral air embolism complicating esophagogastroduodenoscopy (EGD). Endoscopy 2008;40:E191-E192.

2. Sopena-Falco J, Poch-Vall N, Brullet E, et al. Fatal massive air embolism following diagnostic colonoscopy. Endoscopy 2013; 45:E91.

3. Chen N, Lamba R, Lee J, Lall C. Mesenteric air embolism following enteroscopicsmallboweltattooing procedure.JClinImagingSci2012; 2:86.

4. Mittnacht AJ, Sampson I, Bauer J, Reich DL. Air embolism during sigmoidoscopy confirmed by transesophageal echocardiography. $J$ Cardiothorac Vasc Anesth 2006;20:387-389.

5. Jow AZ, Wan D. Complication of cardiac air embolism during ERCP and EUS-assisted cyst-gastrostomy for pancreatic pseudocyst. Gastrointest Endosc 2012;75:220-221.

6. Sun Q, Gao G. Decompression Sickness. N Engl J Med 2017; 377:1568.

7. McGee DC, Gould MK. Preventing complications of central venous catheterization. N Engl J Med 2003;348:1123-1133.

8. Laratta C, Cheung L. Venous air embolism from blunt chest trauma. Can Respir J 2015;22:199-200.

9. Ishii $\mathrm{H}$, Hiraki T, Gobara $\mathrm{H}$, et al. Risk factors for systemic air embolismasacomplication of percutaneousCT-guidedlungbiopsy: multicenter case-control study. Cardiovasc Intervent Radiol 2014; 37:1312-1320.

10. Yadav S, Jain S, Aggarwal P, Gupta R. Systemic arterial air embolism: positive pressure ventilation can be fatal in a patient with blunt trauma. BMJ Case Rep 2013;2013.

11. Adler DG, Baron TH, Davila RE, et al. ASGE guideline: the role of ERCP in diseases of the biliary tract and the pancreas. Gastrointest Endosc 2005;62:1-8.

12. Loperfido S, Angelini G, Benedetti G, et al. Major early complications from diagnostic and therapeutic ERCP: a prospective multicenter study. Gastrointest Endosc 1998;48:1-10.

13. Durant TM, Long J, Oppenheimer MJ. Pulmonary (venous) air embolism. Am Heart J 1947;33:269-281.

14. Lynch JJ, Schuchard GH, Gross CM, Wann LS. Prevalence of right-to-left atrial shunting in a healthy population: detection by Valsalva maneuver contrast echocardiography. Am J Cardiol 1984; 53:1478-1480.

15. Dutka AJ. A review of the pathophysiology and potentialapplication of experimental therapies for cerebral ischemia to the treatment of cerebral arterial gas embolism. Undersea Biomed Res 1985; 12:403-421.

16. van Hulst RA, Klein J, Lachmann B. Gas embolism: pathophysiology and treatment. Clin Physiol Funct Imaging. 2003;23:237-246.

17. Lowdon JD, Tidmore TL, Jr. Fatal air embolism after gastrointestinal endoscopy. Anesthesiology 1988;69:622-623.

18. Desmond PV, MacMahon RA. Fatal air embolism following endoscopy of a hepatic portoenterostomy. Endoscopy 1990;22:236.

19. Gottdiener JS, Papademetriou V, Notargiacomo A, Park WY, Cutler DJ. Incidence and cardiac effects of systemic venous air embolism. Echocardiographic evidence of arterial embolization via noncardiac shunt. Arch Intern Med 1988;148:795-800.

20. Butler BD, Bryan-Brown C, Hills BA. Paradoxical air embolism: transcapillary route. Crit Care Med 1983;11:837.

21. Tommasino C, Rizzardi R, Beretta L, Venturino M, Piccoli S. Cerebral ischemia after venous air embolism in the absence of intracardiac defects. J Neurosurg Anesthesiol 1996;8:30-34.

22. Spencer MP, Oyama Y. Pulmonary capacity for dissipation of venous gas emboli. Aerosp Med 1971;42:822-827.

23. Katzgraber F, Glenewinkel F, Fischler S, Rittner C. Mechanism of 
fatal air embolism after gastrointestinal endoscopy. Int J Legal Med 1998;111:154-156.

24. Romberg C. Systemic air embolism after ERCP: a case report and review of the literature (with video). Gastrointest Endosc 2009;70:1043-1045.

25. Nayagam J, Ho KM, Liang J. Fatal systemic air embolism during endoscopic retrograde cholangio-pancreatography. Anaesth Intensive Care 2004;32:260-264.

26. Espinel J, Pinedo ME, Calleja JL. Portal vein filling: an unusual complication of needle-knife sphincterotomy. Endoscopy 2007; 39:E245.

27. Siegel JH, Ben-Zvi JS, Yatto RP. Portal vein filling during ERCP. Gastrointest Endosc 1993;39:471-472.

28. Ben-Zvi JS, Siegel JH, Yatto R. Opacification of the portal system during ERCP: demonstration of an anomalous pancreatico-portal connection in a patient with pancreatic carcinoma. Gastrointest Endosc 1989;35:445-447.

29. Jorens PG, Van Marck E, Snoeckx A, Parizel PM. Nonthrombotic pulmonary embolism. Eur Respir J 2009;34:452-474.

30. Sisk JM, Choi MD, Casabianca AB, Hassan AM. Two cardiac arrests because of venous air embolism during endoscopic retrograde cholangiopancreatography: a case report. A A Case Rep 2017; 8:47-50.

31. Marchesi M, Battistini A, Pellegrinelli M, Gentile G, Zoja R. Fatal air embolism during endoscopic retrograde cholangiopancreatography (ERCP): An 'impossible' diagnosis for the forensic pathologist. Med Sci Law 2016;56:70-73.

32. Hauser G, Milosevic M, Zelic M, Stimac D. Sudden death after endoscopic retrograde cholangiopancreatography (ERCP)--case report and literature review. Medicine (Baltimore) 2014;93:e235.

33. Stabile L, Cigada M, Stillittano D, et al. Fatal cerebral air embolism after endoscopic retrograde cholangiopancreatography. Acta Anaesthesiol Scand 2006;50:648-649.

34. Mohammedi I, Ber C, Peguet O, Ould-Aoudia T, Duperret S, Petit P. Cardiac air embolism after endoscopic retrograde cholangiopancreatography in a patient with blunt hepatic trauma. J Trauma 2002;53:1170-1172.

35. Trabanco S, Pardo S, Williams M, Diaz J, Ruiz C. Cerebral air embolism after ERCP. J Clin Anesth 2017;36:133-135.

36. Markin NW, Montzingo CR. Paradoxical air embolus during endoscopic retrograde cholangiopancreatography: an uncommon fatal complication. A A Case Rep 2015;4:87-90.

37. Athauda D, Tan GS, De Pablo-Fernandez E. Cerebral air embolism during endoscopic retrograde cholangiopancreatography: treatment with therapeutic hypothermia. Endoscopy 2014;46:E151-E152.

38. Vachalova I, Ernst S, Vynogradova I, Wohrmann S, Heckmann JG. Cerebral air embolism via port catheter and endoscopic retrograde cholangio-pancreatography. Springerplus 2013;2:477.

39. Bechi A, Nucera MP, Olivotto I, Manetti R, Fabbri LP. Complete neurological recovery after systemic air embolism during endoscopic retrograde cholangiopancreatography. Minerva Anestesiol 2012;78:622-625.

40. Painter NP, Kumar PA, Arora H. Acute pulmonary embolism during an endoscopic retrograde cholangiopancreatography. Ann Card Anaesth 2014;17:145-147.

41. Di Pisa M, Chiaramonte G, Arcadipane A, Burgio G, Traina M. Air embolism during endoscopic retrograde cholangiopancreatography in a pediatric patient. Minerva Anestesiol 2011;77:90-92.

42. Smith RM, Van Hoesen KB, Neuman TS. Arterial gas embolism and hemoconcentration. J Emerg Med 1994;12:147-153.

43. Schafer ST, Neumann A, Lindemann J, Gorlinger K, Peters J. Venous air embolism induces both platelet dysfunction and thrombocytopenia. Acta Anaesthesiol Scand 2009;53:736-741.

44. Smith RM, Neuman TS. Elevation of serum creatine kinase in divers with arterial gas embolization. N Engl J Med 1994;330:19-24.
45. Eckmann DM, Armstead SC, Mardini F. Surfactants reduce platelet-bubble and platelet-platelet binding induced by in vitro air embolism. Anesthesiology 2005;103:1204-1210.

46. van Boxel GI, Hommers CE, Dash I, Goodman AJ, Green J, Orme RM. Myocardial and cerebral infarction due to massive air embolism following endoscopic retrograde cholangiopancreatography (ERCP). Endoscopy 2010;42:E80-E81.

47. Ence TJ, Gong H, Jr. Adult respiratory distress syndrome after venous air embolism. Am Rev Respir Dis 1979;119:1033-1037.

48. Kizer KW, Goodman PC. Radiographic manifestations of venous air embolism. Radiology 1982;144:35-39.

49. Wills-Sanin B, Cardenas YR, Polanco L, Rivero O, Suarez S, Buitrago AF. Air embolism after endoscopic retrograde cholangiopancreatography in a patient with budd Chiari syndrome. Case Rep Crit Care 2014;2014:205081.

50. Bastovansky A, Stollberger C, Finsterer J. Fatal cerebral air embolism due to a patent foramen ovale during endoscopic retrograde cholangiopancreatography. Clin Endosc 2014;47:275-280

51. Kalaitzakis E, Stern N, Sturgess R. Portal vein cannulation: an uncommon complication of endoscopic retrograde cholangiopancreatography. World Jastroenterol2011;17:5131-5132.

52. Nern C, Bellut D, Husain N, Pangalu A, Schwarz U, Valavanis A. Fatal cerebral venous air embolism during endoscopic retrograde cholangiopancreatography-case report and review of the literature. Clin Neuroradiol 2012;22:371-374.

53. Marcus RH, Weinert L, Neumann A, Borow KM, Lang RM. Venous air embolism. Diagnosis by spontaneous right-sided contrast echocardiography. Chest 1991;99:784-785.

54. Efthymiou M, Raftopoulos S, Antonio Chirinos J, May GR. Air embolism complicated by left hemiparesis after direct cholangioscopy with an intraductal balloon anchoring system. Gastrointest Endosc 2012;75:221-223.

55. Palmon SC, Moore LE, Lundberg J, Toung T. Venous air embolism: a review. J Clin Anesth 1997;9:251-257.

56. Edmonds-Seal J, Prys-Roberts C, Adams AP. Air embolism. A comparison of various methods of detection. Anaesthesia 1971;26:202-208

57. Maroon JC, Albin MS. Air embolism diagnosed by Doppler ultrasound. Anesth Analg 1974;53:399-402.

58. Edmonds-Seal J, Maroon JC. Air embolism diagnosed with ultrasound. A new monitoring technique. Anaesthesia 1969; 24:438-440.

59. Bedford RF, Marshall WK, Butler A, Welsh JE. Cardiac catheters for diagnosis and treatment of venous air embolism: a prospective study in man. J Neurosurg 1981;55:610-614.

60. Bowdle TA, Artru AA. Treatment of air embolism with a special pulmonary artery catheter introducer sheath in sitting dogs. Anesthesiology 1988;68:107-110.

61. Colley PS, Artru AA. Bunegin-Albin catheter improves air retrieval and resuscitation from lethal venous air embolism in dogs. Anesth Analg 1987;66:991-994.

62. Mathew J, Jr., Parker C, 3rd, Wang J. Pulseless electrical activity arrest due to air embolism during endoscopic retrograde cholangiopancreatography: a case report and review of the literature. BMJ Open Gastroenterol 2015;2:e000046.

63. Annane D, Troche G, Delisle F, et al. Effects of mechanical ventilation with normobaric oxygen therapy on the rate of air removal from cerebral arteries. Crit Care Med 1994;22:851-857.

64. Van Liew HD, Conkin J, Burkard ME. The oxygen window and decompression bubbles: estimates and significance. Aviat Space Environ Med 1993;64:859-865.

65. Raskin JM, Benjamin E, Iberti TJ. Venous air embolism: case report and review. Mt Sinai J Med 1985;52:367-370.

66. Orebaugh SL. Venous air embolism: clinical and experimental considerations. Crit Care Med 1992;20:1169-1177. 
67. Moon RE, de Lisle Dear G, Stolp BW. Treatment of decompression illness and latrogenic gas embolism. Respir Care Clin N Am 1999; 5:93-135.

68. Adornato DC, Gildenberg PL, Ferrario CM, Smart J, Frost EA. Pathophysiology of intravenous air embolism in dogs. Anesthesiology 1978;49:120-127.

69. Sink JD, Comer PB, James PM, Loveland SR. Evaluation of catheter placement in the treatment of venous air embolism. Ann Surg 1976; 183:58-61.

70. Muth CM, Shank ES. Gas embolism. $N$ Engl $J$ Med 2000;342:476-482.

71. Reasoner DK, Ryu KH, Hindman BJ, Cutkomp J, Smith T. Marked hemodilution increases neurologic injury after focal cerebral ischemia in rabbits. Anesth Analg 1996;82:61-67.

72. Lee SH, Heros RC, Mullan JC, Korosue K. Optimum degree of hemodilution for brain protection in a canine model of focal cerebral ischemia. J Neurosurg 1994;80:469-475.

73. Visvanathan A, Dennis M, Whiteley W. Parenteral fluid regimens for improving functional outcome in people with acute stroke. Cochrane Database Syst Rev 2015;9:CD011138.

74. Ropper AH. Hyperosmolar therapy for raised intracranial pressure. N Engl J Med 2012;367:746-752.

75. Patel PM, Drummond JC, Cole DJ, Kelly PJ, Watson M. Isoflurane and pentobarbital reduce the frequency of transient ischemic depolarizations during focal ischemia in rats. Anesth Analg 1998; 86:773-780.

76. Hoffman WE, Charbel FT, Edelman G, Ausman JI. Thiopental and desflurane treatment for brain protection. Neurosurgery 1998; 43:1050-1053.

77. Dentali F, Ageno W, Bozzato S, et al. Role of factor V Leiden or G20210A prothrombin mutation in patients with symptomatic pulmonary embolism and deep vein thrombosis: a meta-analysis of the literature. J Thromb Haemost 2012;10:732-737.

78. Heit JA, Silverstein MD, Mohr DN, Petterson TM, O’Fallon WM, Melton LJ, 3rd. Risk factors for deep vein thrombosis and pulmonary embolism: a population-based case-control study. Arch Intern Med 2000;160:809-815.

79. Cines DB, Kaywin P, Bina M, Tomaski A, Schreiber AD. Heparinassociated thrombocytopenia. N Engl J Med 1980;303:788-795.

80. Kelton JG. Heparin-induced thrombocytopenia. Haemostasis 1986; 16:173-186.

81. Dehring DJ, Arens JF. Pulmonary thromboembolism: disease recognition and patient management. Anesthesiology 1990; 73:146-164.

82. Sapolsky RM, Pulsinelli WA. Glucocorticoids potentiate ischemic injury to neurons: therapeutic implications. Science 1985; 229:1397-1400.

83. Evans DE, Kobrine AI, LeGrys DC, Bradley ME. Protective effect of lidocaine in acute cerebral ischemia induced by air embolism. $J$ Neurosurg 1984;60:257-263.

84. Dutka AJ, Mink R, McDermott J, Clark JB, Hallenbeck JM. Effect of lidocaine on somatosensory evoked response and cerebral blood flow after canine cerebral air embolism. Stroke 1992;23:1515-1520.

85. Bauerle J, Fischer A, Hornig T, Egger K, Wengenmayer T, Bardutzky J. Therapeutic hypothermia in cerebral air embolism: a case report. Springerplus 2013;2:411.

86. Nielsen N, Hovdenes J, Nilsson F, et al. Outcome, timing and adverse events in therapeutic hypothermia after out-of-hospital cardiac arrest. Acta Anaesthesiol Scand 2009;53:926-934.

87. Tovar EA, Del Campo C, Borsari A, Webb RP, Dell JR, Weinstein PB. Postoperative management of cerebral air embolism: gas physiology for surgeons. Ann Thorac Surg 1995;60:1138-1142.

88. Mink RB, Dutka AJ. Hyperbaric oxygen after global cerebral ischemia in rabbits reduces brain vascular permeability and blood flow. Stroke 1995;26:2307-2312.
89. Thom SR, Mendiguren I, Hardy K, et al. Inhibition of human neutrophil beta2-integrin-dependent adherence by hyperbaric O2. Am J Physiol 1997;272:C770-C777.

90. Murphy BP, Harford FJ, Cramer FS. Cerebral air embolism resulting from invasive medical procedures. Treatment with hyperbaric oxygen. Ann Surg 1985;201:242-245.

91. Tibbles PM, Edelsberg JS. Hyperbaric-oxygen therapy. N Engl J Med 1996;334:1642-1648.

92. Colton JB, Curran CC. Quality indicators, including complications, of ERCP in a community setting: a prospective study. Gastrointest Endosc 2009;70:457-467.

93. Maccarone G, Shakoor T, Ellis B. Air embolism after percutaneous transhepatic biliary drainage and subsequent endoscopic retrograde cholangiopancreatography (ERCP). Endoscopy 2011;43:E399.

94. ChaST, Kwon CI, Seon HG, etal. Fatal biliary-systemic air embolism during endoscopic retrograde cholangiopancreatography: a case with multifocal liver abscesses and choledochoduodenostomy. Yonsei Med J 2010;51:287-290.

95. Ishikawa Y, Kishimoto T, Miyai M, Miyamura S, Sagayama T, Itoh N. Bilioportal fistula as a sequela to choledocholithiasis: a case report. J Clin Gastroenterol 1982;4:63-65.

96. Afreen LK, Bryant AS, Nakayama $T$, et al. Incidence of venous air embolism during endoscopic retrograde cholangiopancreatography. Anesth Analg 2018;127:420-423.

97. Kondo H, Naitoh I, Nakazawa T, et al. Development of fatal systemic gas embolism during direct peroral cholangioscopy under carbon dioxide insufflation. Endoscopy 2016;48:E215-E216.

98. Hann A, Zizer E, Egger K, Allescher HD, Meining A. Fatal outcome due to $\mathrm{CO} 2$ emboli during direct cholangioscopy. Gut 2018; 67:1378-1379.

99. Finsterer J, Stollberger C, Bastovansky A. Cardiac and cerebral air embolism from endoscopic retrograde cholangiopancreatography. Eur J Gastroenterol Hepatol 2010;22:1157-1162.

100. Shi H, Chen S, Swar G, Wang Y, Ying M. Carbon dioxide insufflation during endoscopic retrograde cholangiopancreatography: a review and meta-analysis. Pancreas 2013;42:1093-1100.

101. Donepudi S, Chavalitdhamrong D, Pu L, Draganov PV. Air embolism complicating gastrointestinal endoscopy: A systematic review. World J Gastrointest Endosc 2013;5:359-365.

102. Reynolds HR, Hochman JS. Cardiogenic shock: current concepts and improving outcomes. Circulation 2008;117:686-697.

103. Maggino L, Crino SF, Bernardoni L, et al. An unforeseeable adverse event during ERCP. Endoscopy 2016;48:E278-E279.

104. Cooper JS, Thomas J, Singh S, Brakke T. Endoscopic bubble trouble: hyperbaric oxygen therapy for cerebral gas embolism during upper endoscopy. J Clin Gastroenterol 2017;51:e48-e51.

105. Park S, Ahn JY, Ahn YE, et al. Two cases of cerebral air embolism that occurred during esophageal ballooning and endoscopic retrograde cholangiopancreatography. Clin Endosc 2016; 49:191-196.

106. Duburque C, Beaujard E, Landel JB, et al. Life-threatening air embolism during ERCP. Endoscopy 2014;46:E250-E251.

107. Simmons TC. Hepatic portal venous gas due to endoscopic sphincterotomy. Am J Gastroenterol 1988;83:326-328.

108. Barthet M, Membrini P, Bernard JP, Sahel J. Hepatic portal venous gas after endoscopic biliary sphincterotomy. Gastrointest Endosc 1994;40:261-263.

109. Merine D, Fishman EK. Uncomplicated portal venous gas associated with duodenal perforation following ERCP: CT features. J Comput Assist Tomogr 1989;13:138-139.

110. Arora A, Mukund A, Garg H, Patidar Y. Portal venous air embolization. Turk J Gastroenterol 2013;24:374-375.

111. Barbeiro S, Atalaia-Martins C, Goncalves C, Cotrim I. Portal air embolism after endoscopic retrograde cholangiopancreatography. Rev Esp Enferm Dig 2017;109:452-453. 
112. Siddiqui J, Jaffe PE, Aziz K, et al. Fatal air and bile embolism after percutaneous liver biopsy and ERCP. Gastrointest Endosc 2005; 61:153-157.

113. Chavalitdhamrong D, Draganov PV. Acute stroke due to air embolism complicating ERCP. Endoscopy 2013;45:E177-E178.

114. Goins KM, May JM, Hucklenbruch C, Littlewood KE, Groves DS. Unexpected cardiovascular collapse from massive air embolism during endoscopic retrograde cholangiopancreatography. Acta Anaesthesiol Scand 2010;54:385-388.

115. Bisceglia M, Simeone A, Forlano R, Andriulli A, Pilotto A. Fatal systemic venous air embolism during endoscopic retrograde cholangiopancreatography. Adv Anat Pathol 2009;16:255-262.

116. Tan BK, Saunier CF, Cotton F, Gueugniaud PY, Piriou V. Thoracoabdominal CT scan: a useful tool for the diagnosis of air embolism during an endoscopic retrograde cholangiopancreatography. Ann Fr Anesth Reanim 2008;27:240-243.

117. Kennedy C, Larvin M, Linsell J. Fatal hepatic air embolism following ERCP. Gastrointest Endosc 1997;45:187-188.
118. Rabe C, Balta Z, Wullner U, et al. Biliary metal stents and air embolism: a note of caution. Endoscopy 2006;38:648-650.

119. Fernandez-Fernandez J, Real-Noval H, Rodriguez-Rodriguez E. Massive cerebral air embolism following endoscopic retrograde cholangiopancreatography. A case report and review of the literature. Rev Neurol 2016;63:497-500.

120. Giuly E, Pesenti C, Pernoud N, Bories E, Francon D. Air embolism: an unusual complication of endoscopic retrograde cholangiopancreatography. Ann Fr Anesth Reanim 2005;24:1400-1403.

121. Rangappa P, Uhde B, Byard RW, Wurm A, Thomas PD. Fatal cerebral arterial gas embolism after endoscopic retrograde cholangiopancreatography. Indian J Crit Care Med 2009;13:108-112.

122. Arguelles Garcia B, Garcia Blanco A, Meilan Martinez A, Calvo Blanco J. Cerebral artery air embolism secondary to endoscopic retrograde cholangiopancreatography. Gastroenterol Hepatol 2009;32:614-617. 